\title{
ALONG WIND ANALYSIS OF REINFORCED CONCRETE CHIMNEYS
}

\author{
K.R.C. Reddy ${ }^{1}$ \\ ${ }^{1}$ Professor, Dept. of Civil Engineering, Anurag Group of Institutions, Venkatapur, Hyderabad-88, India
}

\begin{abstract}
Along wind analysis of tall reinforced concrete $(R C)$ chimneys by random vibration approach and Codal methods of India (IS 4998 (part 1)), America (ACI 307) and Australia (AS/NZS 1170.2) are presented in this paper. For the analysis based on random vibration approach, the RC chimney is modeled as multi-degree-of freedom system subjected to static load due to mean component of wind velocity and dynamic load due to fluctuating component of velocity. The fluctuating component of wind velocity at a point is considered as temporal random process. Next, the codal procedures for along-wind analysis of tall RC chimneys from Indian, American and Australian codes are reviewed. Four RC chimneys are analyzed using these methods to obtain their responses. It is found that the codal methods of along-wind analysis are simplistic, are not equipped to estimate the deflection of the chimneys and producing varied results. The simplifying assumptions used in these codes are discussed.
\end{abstract}

Keywords: Wind velocity, Random vibration, Wind response, Gust Factor, Power spectral density.

$$
\text { - *** }
$$

\section{INTRODUCTION}

Wind loads depend on wind velocity which varies with time and location. At any location, the temporal variation of wind velocity comprises of a mean component and fluctuating component. The mean component of velocity which is time invariant exerts static load and the fluctuating component exerts dynamic load on the structure. The temporal variation of fluctuating component is modeled as random process (or stochastic process) and is considered to be Gaussian (Daveport (1962, 1963, 1967), Vellozzi (1968), Nigam and Narayanan (1994)). The temporal variation of velocity changes with location of point along the height and width of structure. The time variation of wind velocity at any two locations is considered to be correlated with a correlation function.

The response of structure to along-wind load is obtained by considering the structure as a dynamical system subjected to stochastic loads. Response of structure is obtained in terms of statistical quantities like power spectral density, variance, peak values etc. The details of all the steps in random vibration analysis are discussed in this paper. These details are taken from Davenport (1962, 1963, 1967), Solari (1982), Nigam and Narayanan (1994), Simiu and Scanlan (1996).

The stochastic dynamic analysis mentioned above is quite involved and can not be used in the design offices for routine design works. Hence, codes of practice make certain simplifying assumptions and give simplified procedures for obtaining along-wind response of structures.

First the analysis using random vibration approach is done, then the methods of India, America and Australia codes are described. It is noted that all the codes have given simplified expressions after making certain assumptions. The differences in the along-wind response obtained from various methods are discussed.

\section{METHODS OF ANALYSIS}

The following methods are studied to estimate the alongwind response of RC chimneys.

1. Random vibration analysis

2. IS 4998 (part 1) method

3. ACI 307 method

4. AS/NZS 1120.2 method

\subsection{Random Vibration Analysis}

The details of random vibration analysis are taken from Davenport (1962, 1963 and 1967). The instantaneous wind velocity, $U(z, t)$, comprises of mean component and fluctuating component.

$$
U(z, t)=\bar{U}(z)+u[(z, t)
$$

$u(z, t)$ represents random fluctuations about the mean wind which is called gust component.

The mean component of wind velocity is time invariant and its variation along height is given by logarithmic law (Simiu and Scanlan, (1996))

$$
\bar{U}(z)=2.5 u_{*} \ln \frac{z}{z_{0}}
$$

where, $u^{*}$ is the shear velocity in $\mathrm{m} / \mathrm{s}$ and $z 0$ is the roughness length in $\mathrm{m}$.

The fluctuating component, $u(z, t)$, at any height, $z$ is modeled as Gaussian random process and is quantified in terms of power spectral density (PSD), $S u(z, n)$. 
By Bernoulli's hypothesis (Simiu and Scanlan (1996) and Holms (2001)), the drag force due to wind velocity is given as

$$
F_{D}(z, t)=\frac{1}{2} \rho C_{D} U^{2}(z, t) A
$$

where, $A$ is the area of chimney normal to the wind flow per unit height at the level $z, C D$ is the drag coefficient and $\rho$ is the mass density of wind.

By substituting eq. (1) in eq. (3) and neglecting the second order terms, one gets

$F_{D}(z, t)=\frac{1}{2} \rho C_{D} \bar{U}^{2}(z) D(z)+\rho C_{D} \bar{U}(z) u \llbracket(z, t) D(z)$

In the above expression, the mean load component which is time invariant is given by

$$
\bar{F}_{D}(z)=\frac{1}{2} \rho C_{D} \bar{U}^{2}(z) D(z)
$$

and the fluctuating load component is given by

$$
F_{D}(z, t)=\rho C_{D} \bar{U}(z) u \llbracket(z, t) D(z)
$$

The power spectral density (PSD) and variance of fluctuating wind load component are respectively given by

$$
\begin{aligned}
& S_{F D}(z, n)=\left(\rho C_{D} \bar{U}(z) D(z)\right)^{2} \int_{0}^{\infty} S_{u}(z, n) d n \\
& \sigma_{F D}{ }^{2}(z)=\left(\rho C_{D} \bar{U}(z) D(z)\right)^{2} \sigma_{u}{ }^{2}(z)
\end{aligned}
$$

The mean square value of the velocity fluctuations is given by

$$
\sigma_{u}{ }^{2}=\int_{0}^{\infty} S_{u}(z, n) d n
$$

Where, $\operatorname{Su}(z, n)$ is the PSD of velocity of fluctuating wind component. Simiu (1974) and Solari (1982) have given the following expression for the spectral density, $\operatorname{Su}(z, n)$

$$
S_{u}(z, n)=0.26 \frac{n z}{\bar{U}(z)}^{-2 / 3} \frac{u_{*}^{2}}{n}
$$

where, $\mathrm{n}$ is the frequency. The above PSD of velocity fluctuations is applicable in high frequency range (frequency $>0.2 \mathrm{~Hz}$ ) and in the low frequency range (frequency $<0.2$ $\mathrm{Hz}$ ), the variance of velocity fluctuations is given by

$$
\sigma_{u}^{2}=\beta u_{*}^{2}
$$

where, $\beta$ is a constant, for engineering purpose it is assumed $\beta=6$ and $u^{*}=2.2 \mathrm{~m} / \mathrm{s}$ (Solari, 1982).

The peak value of chimney displacement at level $\mathrm{z}$ is given by

$$
\mathrm{x}(\mathrm{z})=\overline{\mathrm{x}}(\mathrm{z})+\mathrm{g}_{\mathrm{x}}(\mathrm{z}) \cdot \sigma_{x}(\mathrm{z})
$$

where, $\sigma \mathrm{x}$ the resultant root mean square value of the fluctuating component of the wind response (Reddy (2012)), $\mathrm{x}(\mathrm{z})$ is the mean displacement, $\mathrm{gx}(\mathrm{z})$ is the peak factor given by

$$
g_{x}(z)=\sqrt{2 \ln \left[v_{x}(z) T\right]}+\frac{0.577}{\sqrt{2 \ln \left[v_{x}(z) T\right]}}
$$

where, $\mathrm{V}_{x}(z)$ represents the expected frequency, that is, the number of times the mean value is crossed in duration of $T$ and $T$ is the duration of the wind loading, means the time over which mean velocity is averaged is taken as $3600 \mathrm{sec}$ (Simiu and Scanlan (1996). For Gaussian stationary random process, $x(z)$ is given by

$$
v_{x}{ }^{2}(z)=\frac{\int_{0}^{\infty} n^{2} S_{x}(z, n) d n}{\int_{0}^{\infty} S_{x}(z, n) d n}
$$

Peak tip deflection is calculated for each mode separately, and then the corresponding shear force and bending moments are obtained for the first three modes by using the following eqs. (15) and (16). Final shear force and bending moment at a section $\mathrm{z}$ is calculated by SRSS rule.

$$
F_{z 0 i}=4 \pi^{2} f_{i}^{2} \eta_{0 i} \int_{z 0}^{h} m_{z} \varphi_{z i} d z
$$

$$
M_{z 0 i}=4 \pi^{2} f_{i}^{2} \eta_{0 i} \int_{z 0}^{h} m_{z} \varphi_{z i}\left(z-z_{0}\right) d z
$$

where, $f i=$ natural frequency of the chimney in $\mathrm{Hz}$ in the $i^{\text {th }}$ mode of vibration, $m z=$ mass per unit length of the chimney 
at section $z$. The gust factor, $\mathrm{G}=x(z) / x(z)$ is obtained by,

$$
G=1+g_{x}(z) \cdot \frac{\sigma_{x}(z)}{\bar{x}(z)}
$$

\subsection{Codal Methods}

For the analysis of chimneys, the procedures given in the Codes of India (IS 4998 (part 1)), America (ACI 307) and Australia (AS/NZS 1170.2) are used.

\section{DETAILS OF CHIMNEYS ANALYZED}

In the present study, four chimneys are considered. Along wind loads using all the above discussed methods/codes are obtained. Two chimneys are of uniform taper with $180 \mathrm{~m}$ and $220 \mathrm{~m}$ height and the other two chimneys are of height $217 \mathrm{~m}$ and $273 \mathrm{~m}$ with varying taper. For chimney shell M30 grade concrete is used in all the cases, except in the case of $217 \mathrm{~m}$ chimney, M25 grade concrete is used beyond the $138 \mathrm{~m}$ level. The weight density is adopted as $25 \mathrm{kN} / \mathrm{m} 3$. Young's

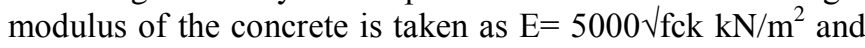
the Poisson's ratio considered as 0.15 .

\subsection{Dynamic Characteristics Of Chimneys}

Chimneys are modeled as vertical cantilever fixed at the base and free at top. Standard software is used to model the cantilever beam with varying cross sections using beam elements. Cantilever beam model is considered along the yaxis and it is constrained to vibrate only in $x-y$ plane along the $\mathrm{x}$-axis. Chimneys are divided into elements of $1 \mathrm{~m}$ length along height. Free vibration characteristic, i.e., modal frequencies, mode shapes and modal masses are obtained from the modal analysis and presented in the Table-1. And a typical mode shapes of chimneys is shown in Fig. 1.

Table-1: Modal frequencies and modal masses of chimneys

\begin{tabular}{|c|c|c|c|c|c|c|c|c|}
\hline \multirow{2}{*}{$\begin{array}{c}\text { Mode } \\
\text { No }\end{array}$} & \multicolumn{2}{|c|}{$180 \mathrm{~m}$} & \multicolumn{2}{c|}{$217 \mathrm{~m}$} & \multicolumn{2}{c|}{$220 \mathrm{~m}$} & \multicolumn{2}{c|}{$273 \mathrm{~m}$} \\
\cline { 2 - 10 } & $\begin{array}{c}\text { Freq. } \\
(\mathrm{Hz})\end{array}$ & $\begin{array}{c}\text { modal } \\
\text { mass }\end{array}$ & $\begin{array}{c}\text { Freq. } \\
(\mathrm{Hz})\end{array}$ & $\begin{array}{c}\text { modal } \\
\text { mass }\end{array}$ & $\begin{array}{c}\text { Freq. } \\
(\mathrm{Hz})\end{array}$ & $\begin{array}{c}\text { modal } \\
\text { mass }\end{array}$ & $\begin{array}{c}\text { Freq. } \\
(\mathrm{Hz})\end{array}$ & $\begin{array}{c}\text { modal } \\
\text { mass }\end{array}$ \\
\hline 1 & 0.28 & 41.54 & 0.34 & 39.50 & 0.45 & 44.44 & 0.23 & 34.99 \\
\hline 2 & 1.09 & 62.60 & 1.39 & 61.25 & 1.86 & 65.24 & 1.04 & 56.87 \\
\hline 3 & 2.63 & 72.91 & 3.44 & 72.05 & 4.54 & 74.70 & 2.62 & 68.21 \\
\hline 4 & 4.89 & 78.85 & 4.25 & 72.05 & 5.02 & 74.70 & 3.65 & 68.21 \\
\hline 5 & 6.46 & 78.85 & 6.45 & 78.19 & 8.36 & 79.92 & 4.91 & 75.00 \\
\hline 6 & 7.86 & 82.65 & 9.64 & 78.19 & 11.88 & 79.92 & 7.91 & 79.35 \\
\hline 7 & 11.51 & 85.27 & 10.28 & 81.99 & 13.18 & 83.14 & 8.76 & 79.35 \\
\hline 8 & 14.74 & 85.27 & 14.93 & 84.58 & 18.84 & 85.28 & 11.64 & 82.71 \\
\hline 9 & 15.82 & 87.17 & 16.10 & 84.58 & 19.18 & 85.28 & 14.43 & 82.71 \\
\hline 10 & 20.73 & 88.60 & 20.20 & 86.32 & 25.17 & 86.78 & 15.71 & 84.44 \\
\hline
\end{tabular}

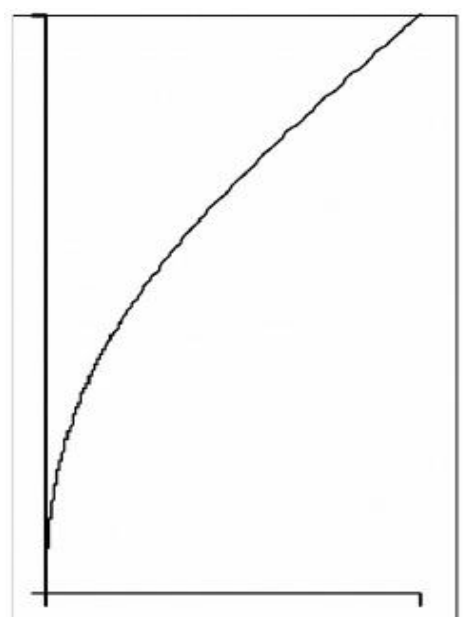

0.0

$1^{\text {st }}$ mode

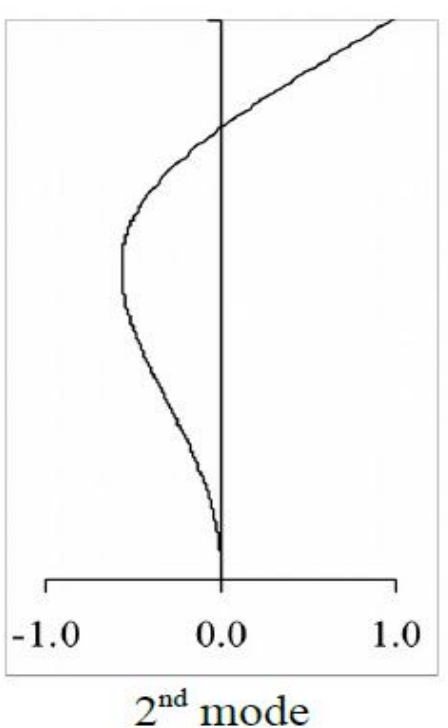

$2^{\text {nd }}$ mode

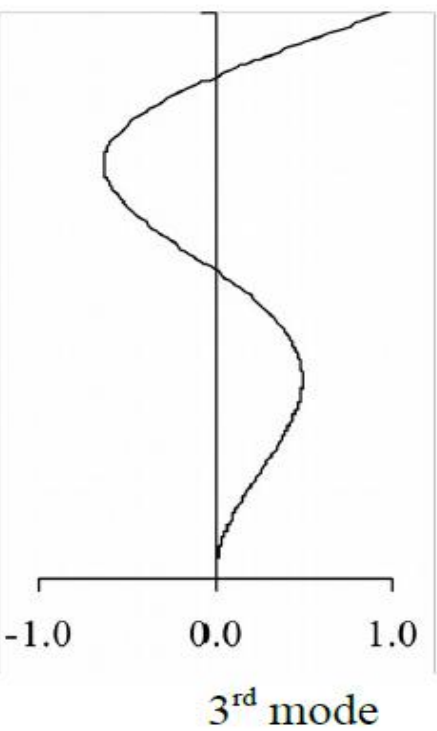

$3^{\text {rd }}$ mode

Fig-1: Typical mode shapes of a chimney 
For random vibration analysis first three modes, in which about $75 \%$ mass gets excited are assumed. In some of the higher modes, axial modes are also getting excited. For example in $180 \mathrm{~m}$ chimney, $5^{\text {th }}$ mode has axial mode and no mass gets excited in $\mathrm{x}$-direction.

\section{RESULTS OF ALONG WIND ANALYSIS}

In this study numerical results on along wind response (i.e., deflection, bending moment (BM) and shear force (SF)) are obtained from each of the methods discussed above. In the random vibration analysis the wind is specified in terms of mean wind profile and PSD of fluctuating component of wind velocity (Davenport (1962, 1963, 1967), Solari (1982), Nigam and Narayanan (1994), Simiu and Scanlan (1996)). In the description of PSD of wind velocity, influence of correlation between wind velocities at two different locations is also accounted (Simiu and Scanlan (1996)). In the random vibration analysis, mean response is, i.e., deflection due to mean component is obtained as static response. The deflection due to fluctuating response is obtained in terms of PSD of deflection. The total deflection is obtained by adding the mean response and the standard deviation of fluctuating component. In random vibration analysis, sufficient number of modes is to be used to get reasonably converged results. For a typical RC chimney, about $75 \%$ of mass gets excited in the first three modes.

\subsection{Results From Random Vibration Analysis}

A FORTRAN program is developed to get the deflection, bending moment and shear force using random vibration analysis as per the steps presented in the section 2.1. The other parameters taken as follows:

Friction velocity, $u^{*}=2.2 \mathrm{~m} / \mathrm{s}$

Density of air, $\rho=1.2 \mathrm{~kg} / \mathrm{m}^{3}$,

Roughness length for terrain, $z 0=0.07 \mathrm{~m}$,

Averaging time, $T=600 \mathrm{sec}$.,

Damping ratio, $\eta=0.016$

Wind ward pressure coefficient,

$C w=0.8$

Leeward pressure coefficient, $\mathrm{Cl}=0.0$

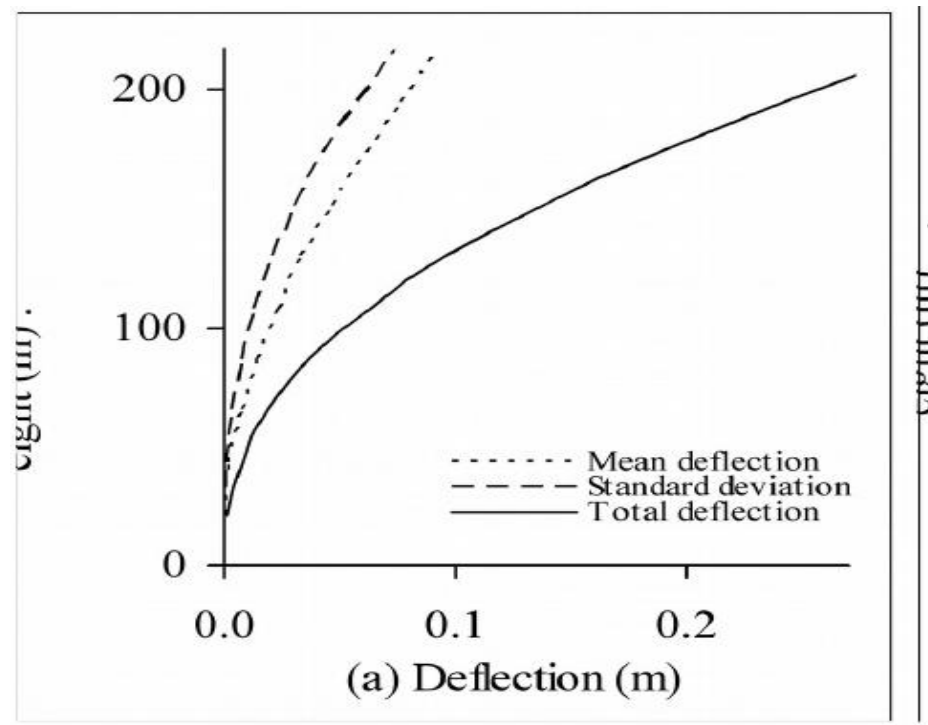

The results of all fours chimneys are obtained and presented in the Table-2. The variation of parameters for chimney 217 $\mathrm{m}$ is shown in Fig. 2 and 3. Similar kind of variation pattern is seen for all other chimneys.

The power spectral density of tip deflection is shown in Fig. 2 . The results of mean deflection $x(z)$, standard deviation of fluctuating component $\sigma x(z)$ and total deflection $x(z)$ is shown in Fig. 3(a). And the variation of gust factor $(G)$ with height (eq. 17) is shown in Fig. 3(b). It should be noted that $G$ is varying with height and its value ranges from 2.30 to 3.27. The variation of shear force and bending moment along the height is shown in Fig. 3(c) and (d) respectively. It is noted that the peak tip deflection is $0.302 \mathrm{~m}$, and base shear and base moment are $4056 \mathrm{kN}$ and $627096 \mathrm{kNm}$ respectively.

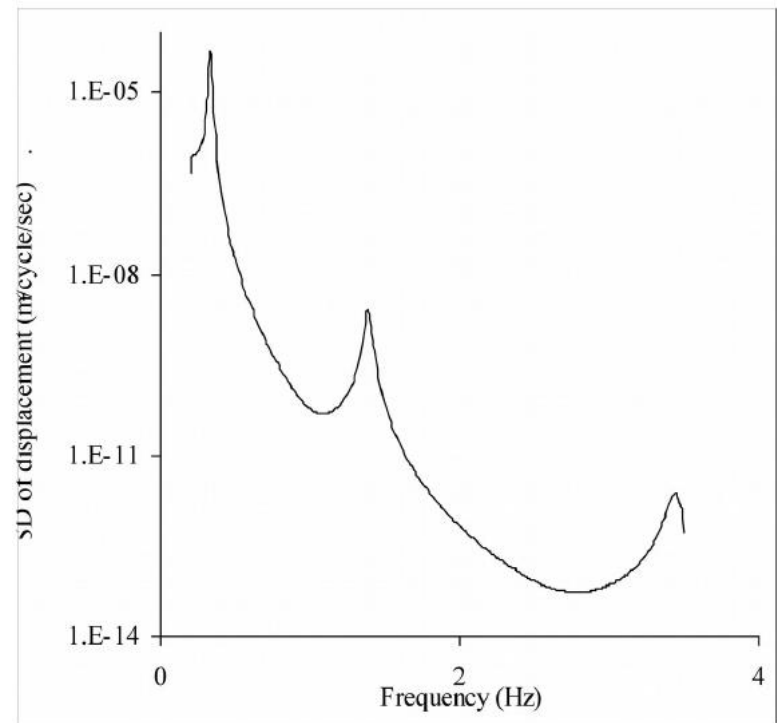

Fig 2: PSD of tip deflection of 217 m chimney

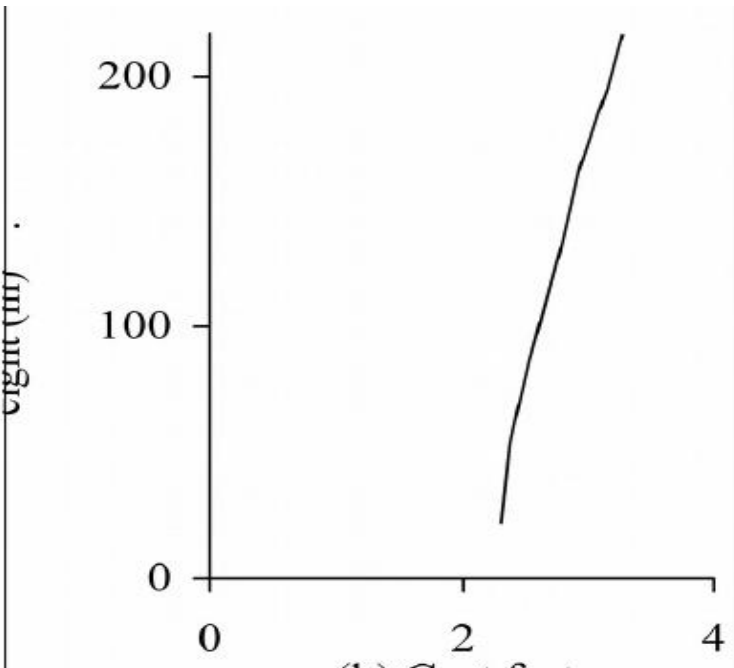

(b) Gust factor 


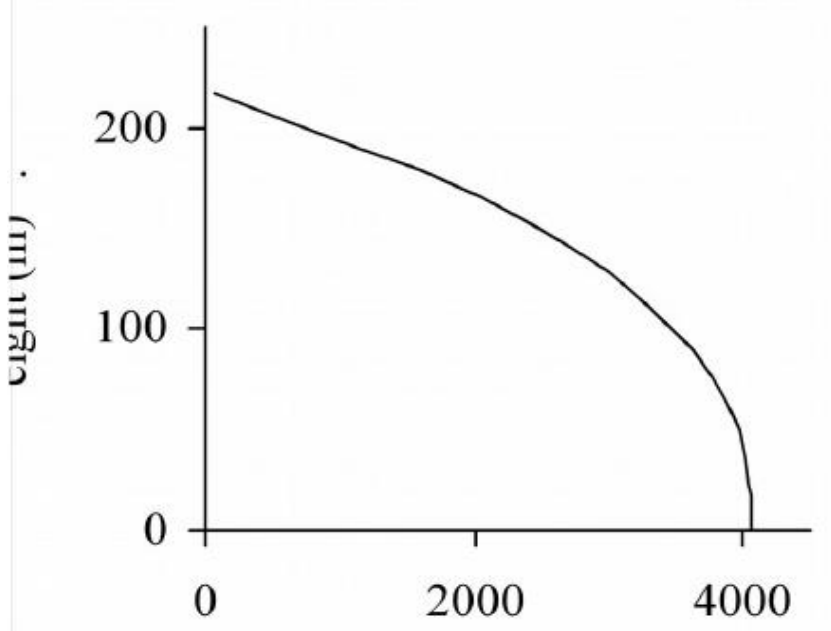

(c) Shear force $(\mathrm{kN})$

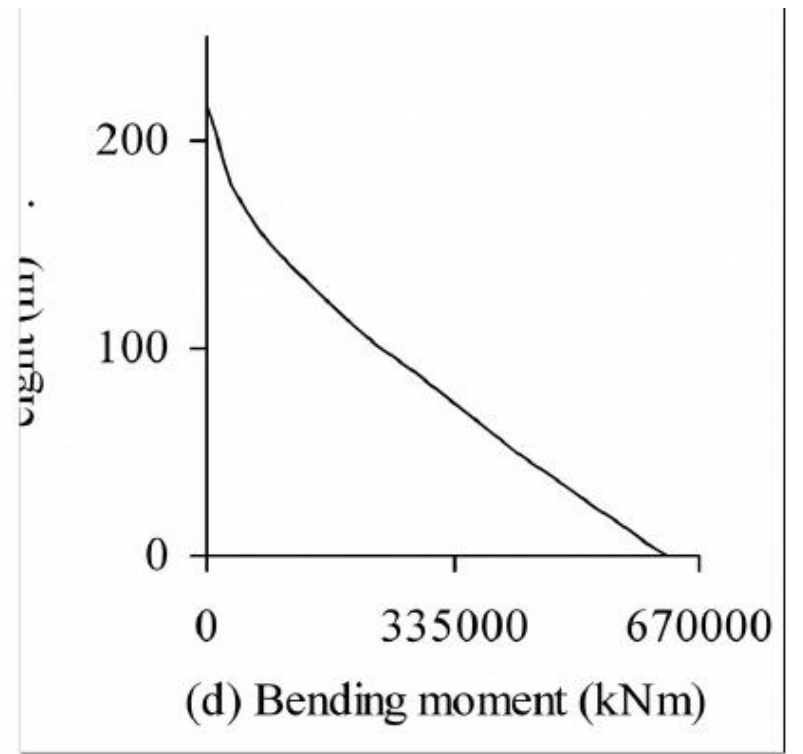

(d) Bending moment $(\mathrm{kNm})$

Fig 3: Along-wind response of $217 \mathrm{~m}$ chimney

\subsection{Results from Codes}

Codal methods are simplified version of random vibration analysis. In Indian and American codes, mean and fluctuating components are obtained separately. However, mode shapes are not used in the calculation of fluctuating component. In AS/NZS code only one component is used. The simplified method of IS code also uses only one component. The simplified method of Indian and AS/NZS codes uses the 3sec gust velocity. Whereas, random response method of Indian and American codes use hourly mean wind velocity to evaluate mean and fluctuating components. The results are presented in the Table- 2 .

Table 2: Along-wind analysis results

\begin{tabular}{|c|l|c|c|c|c|c|c|c|}
\hline \multirow{2}{*}{$\begin{array}{c}\text { Sr. } \\
\text { no. }\end{array}$} & Method & \multicolumn{2}{|c|}{ Chimney } & \multicolumn{6}{|c|}{ Along wind response } \\
\cline { 2 - 8 } & no. & $\begin{array}{c}\text { Ht. } \\
(\mathrm{m})\end{array}$ & $\begin{array}{c}\text { Peak tip } \\
\text { deflect- } \\
\text { tion (m) }\end{array}$ & $\begin{array}{c}\text { Peak } \\
\text { Gust } \\
\text { factor }\end{array}$ & $\begin{array}{c}\text { Gust } \\
\text { factor } \\
\text { used }\end{array}$ & $\begin{array}{c}\text { Base } \\
\text { shear } \\
(\mathrm{kN})\end{array}$ & $\begin{array}{c}\text { Base } \\
\text { moment } \\
(\mathrm{kNm})\end{array}$ \\
\hline 1 & Random & 1 & 180 & 0.836 & 3.58 & - & 1605 & 188593 \\
& vibration & 2 & 217 & 0.302 & 3.27 & - & 4056 & 627096 \\
& analysis & 3 & 220 & 0.207 & 3.24 & - & 5001 & 732210 \\
& & 4 & 273 & 0.597 & 3.15 & - & 4703 & 969309 \\
\hline 2 & IS 4998:1992 & 1 & 180 & - & - & - & 1747 & 151983 \\
& Simplified & 2 & 217 & - & - & - & 5098 & 558208 \\
& Method & 3 & 220 & - & - & - & 5789 & 633948 \\
& & 4 & 273 & - & - & - & 7492 & 836642 \\
\hline 3 & IS 4998:1992 & 1 & 180 & - & 2.14 & 1.14 & 1955 & 202190 \\
& Random & 2 & 217 & - & 1.94 & 0.94 & 5408 & 681998 \\
& Response & 3 & 220 & - & 1.83 & 0.83 & 5828 & 733266 \\
& Method & 4 & 273 & - & 1.92 & 0.92 & 7542 & 1180723 \\
\hline 4 & ACI 307:1998 & 1 & 180 & - & 2.01 & 1.01 & 1753 & 184918 \\
& Method & 2 & 217 & - & 1.77 & 0.77 & 5050 & 658495 \\
& & 3 & 220 & - & 1.78 & 0.78 & 5684 & 743502 \\
& & 4 & 273 & - & 1.78 & 0.78 & 7163 & 1160438 \\
\hline 5 & AS/NZS & 1 & 180 & - & 1.91 & 1.05 & 1519 & 136620 \\
& 1170.2:2002 & 2 & 217 & - & 1.73 & 0.98 & 3192 & 356014 \\
& Method & 3 & 220 & - & 1.69 & 0.96 & 3354 & 376258 \\
& & 4 & 273 & - & 1.72 & 1.01 & 4588 & 631300 \\
\hline
\end{tabular}




\section{DISCUSSION OF RESULTS}

A comparative study is made on the results presented in the Table 2 and following important points are noted:

i. The results obtained by simplified method of IS code and AS/NZS codes are on lower side. In these methods, the codes have used only one component of wind load whereas in other methods or in general; wind load at any height has two components namely mean and fluctuating component.

Basic wind speed of $44 \mathrm{~m} / \mathrm{s}$ is used in these methods. In simplified method of IS code, terrain height and structure size factor $(k 2)$ is used to evaluate the design wind speed which is varying from 0.93 to 1.28 for a structure of height $300 \mathrm{~m}$. The corresponding term in the AS/NZS code is terrain/height multiplier ( $\mathrm{Mz}, \mathrm{cat})$ which is varying from 0.91 to 1.32 .

In the simplified method of IS code, a drag coefficient $(C D)$ of 0.8 is used, which is constant for any height of chimney. The corresponding term in AS/NZS code is aerodynamic shape factor ( $C$ fig) in which a drag coefficient of $C d$ is used which vary with height of chimney in a range of 0.52 to 0.58 depending on average height of surface roughness and outside diameter of chimney.

In addition AS/NZS code uses the dynamic response factor $(C d y n)$ to evaluate the wind loads along the height of chimney. The factor $C d y n$ evaluated by taking into consideration of design wind speed at the top of chimney, along with other parameters. It is found that the Cdyn is constant for any height and depending on the total height of the chimney. The range of $C d y n$ is noted as 0.96 to 1.05 for evaluation of along wind loads. Hence, the results obtained by AS/NZS code are on lower side compared with the simplified method of IS method.

ii. The results obtained by AC1307 method and IS 4998 random response method are reasonably matching. In these methods, the wind load at any height of chimney contains two components viz. mean component and fluctuating component.

The expression for evaluating the mean component by both these methods is same, but the values adopted for the parameters in the expressions are different. A constant drag coefficient $(C D)$ of 0.8 is used in IS code RR method for evaluating the mean component of wind loads at any height of chimney, where in ACI code method the corresponding drag coefficient is varying with height of chimney in a range of 0.65 to 1.00 . Some difference is also exists in the wind profile adopted by these methods though they have used the hourly mean wind speed with the basic wind speed of $44 \mathrm{~m} / \mathrm{s}$.

For evaluating the fluctuating component, IS and ACI methods have used the gust factor calculated by simplified expressions. The gust factor used by IS 4998 method is constant for any height of chimney and is modified to obtain the fluctuating component of wind load. In ACI 1307 method the gust factor evaluated for along wind fluctuating load is also constant for any height of chimney. Gust factor used by both these methods are depending on hourly mean design wind speed at $10 \mathrm{~m}$ level and natural frequency in the case of IS code and the time period in the case of ACI code of the fundamental mode of the chimney. However, there is a small difference in values of gust factor obtained by both these methods. The difference in values of gust factor reflected in the results of base shear and base moment as shown in Table-2.

iii. In random vibration analysis, the total deflection which contains both mean and fluctuating components, is obtained in terms of power spectral density and variance.

The shear force and bending moment are estimated by using eqs. (15) and (16) respectively. Random vibration results are on slightly lower side as compared to random response method of IS and ACI codes.

As such in random vibration method, the gust factor is not used directly to evaluate the fluctuating component as it is used in ACI and RR method of IS 4998 code. However, it is found that the gust factors estimated by random vibration analysis are varying with the height of chimney. The peak value of gust factors obtained for all four chimneys are given in Table 2. The equivalent gust factor from random vibration analysis is ranges from 1.17 to 2.58 .

\section{CONCLUSION}

- Present Codal methods of along-wind analysis are found simplistic and are not equipped to estimate the deflection of the chimneys.

- The results obtained by IS 4998 method are on higher side compared with the ACI 307 method.

- Different codes are giving the different results though the basic parameters are same.

- $\quad$ Along-wind analysis using random vibration approach is quite rigorous method and shall be included in the codes.

\section{ACKNOWLEDGEMENTS}

The author is very much thankful to the management and the administration of the Anurag Group of Institutions, Venkatapur for their support and assistant for presentation of this paper.

\section{REFERENCES}

[1] ACI 307-1998, "Standard Practice for design and construction of RC chimneys (ACI 307-98) and commentary (ACI 307 R-98).” American Concrete Institute, Detroit. 
[2] AS/NZS 1170.2-2002, 'Structural Design actions: Part-2 wind actions', Austrian/New Zealand Standards, Sydney.

[3] Devenport, A.G. (1962). "The application of statistical concept to the wind loading of structures." Proc. of Institution of Civil Engineers, ASCE, 6480, 449-472.

[4] Devenport, A.G. (1963). "The response of slender, line-like structures to a gusty wind." Proc. of Institution of Civil Engineers, ASCE, 6610, 389-408.

[5] Davenport, A.G. (1967). "Gust loading factors." J. of the structural Division, Proc. of the ASCE, Vol. 93, No. ST3,11-33.

[6] IS 875(Part-3)-1987 (reaffirmed 1997). "Code of practice for design loads (other than earthquake) for building and structures," Bureau of Indian Standards, New Delhi.

[7] IS: 4998(Part-i)-1992. "Criteria for design of reinforced concrete chimneys." Bureau of Indian Standards, New Delhi.

[8] Menon, D., and Srinivasrao, P. (1997). "Estimation of along wind moments.” in RC chimneys', J. Engg. Str., 19(1), 71-78.

[9] Menon, D., and Srinivasrao, P. (1997b). "Uncertainties in Codal recommendations for acrosswind load analysis of RC chimneys." J. Wind Engg. \& Ind. Aero., 72, 455-468.

[10] NISA IV, User's Manual, (2007), “Engineering mechanics research corporation." version 15.0, Tory Michigan, USA.

[11] Nigam, N.C., and Narayanan, S. (1994). "Application of Random Vibrations." Narosa Publishing House, New Delhi.

[12] Reddy, K.R.C. (2012), "Control of wind response of tall RC chimneys using tuned mass dampers." $\mathrm{Ph}$. D. Thesis submitted to VNIT Nagpur, India, May 2012

[13] Solari, G., and Pagnini, L.C. (1999). "Gust buffeting and aeroelastic behavior of poles and monotubular towers." J. of Fluids and Structures, 13, 877-905.

[14] Simiu, E., and Scanlan, R.H. (1996). "Wind Effects on Structures-fundamentals and applications to design.” John Willey \& John, INC, $3^{\text {rd }}$ Edition, New York.

[15] Solari, G. (1982). "Along wind response estimation: closed form solution.” J. Structural Division, ASCE, ST1, 225-244.

[16] Vellozzi, J., and Cohen,E. (1968). "Gust response factors.” J. Struct. Div., ASCE, 94, ST6, 1295-1313. 